University of Nebraska - Lincoln

DigitalCommons@University of Nebraska - Lincoln

Faculty Publications, Department of Psychology

Psychology, Department of

2014

\title{
Disputed Paraphilia Diagnoses and Legal Decision Making: A Case Law Survey of Paraphilia NOS, Nonconsent
}

Christopher M. King

Drexel University, kingch@montclair.edu

Lindsey E. Wylie

University of Nebraska-Lincoln, slwylie@unomaha.edu

Eve M. Brank

University of Nebraska-Lincoln, ebrank2@unl.edu

Kirk Heilbrun

Drexel University, kirk.heilbrun@drexel.edu

Follow this and additional works at: https://digitalcommons.unl.edu/psychfacpub

Part of the Criminal Law Commons, Criminal Procedure Commons, Criminology Commons, Law and Psychology Commons, Legal Theory Commons, Psychology Commons, Social Control, Law, Crime, and Deviance Commons, and the Social Policy Commons

King, Christopher M.; Wylie, Lindsey E.; Brank, Eve M.; and Heilbrun, Kirk, "Disputed Paraphilia Diagnoses and Legal Decision Making: A Case Law Survey of Paraphilia NOS, Nonconsent" (2014). Faculty Publications, Department of Psychology. 973.

https://digitalcommons.unl.edu/psychfacpub/973

This Article is brought to you for free and open access by the Psychology, Department of at DigitalCommons@University of Nebraska - Lincoln. It has been accepted for inclusion in Faculty Publications, Department of Psychology by an authorized administrator of DigitalCommons@University of Nebraska - Lincoln. 


\title{
Disputed Paraphilia Diagnoses and Legal Decision Making: A Case Law Survey of Paraphilia NOS, Nonconsent
}

\author{
Christopher M. King, ${ }^{1}$ Lindsey E. Wylie, ${ }^{2}$ Eve M. Brank, ${ }^{2}$ \\ and Kirk Heilbrun ${ }^{3}$
}

1. Department of Psychology and School of Law, Drexel University, Philadelphia, Pennsylvania, USA

2. Department of Psychology, University of Nebraska-Lincoln, Lincoln, Nebraska, USA

3. Department of Psychology, Drexel University, Philadelphia, Pennsylvania, USA

Corresponding author - Christopher M. King, Department of Psychology, Drexel University, 3141 Chestnut Street, Stratton Suite 119, Philadelphia, PA 19104, email chris.king@drexel.edu

\begin{abstract}
Paraphilia diagnoses applied in forensic settings are an ongoing subject of debate among psycholegal professionals and scholars. Disagreements pertain to both means-related issues having to do with issues of diagnostic reliability and validity, and ends-related issues regarding the consequences inherent to the legal contexts in which the diagnoses arise. To provide a fresh outlook on some of the issues, the present study entailed a systematic survey of U.S. case law to investigate the history, extent, and nature of forensic uses of a controversial paraphilia diagnosis, paraphilia not otherwise specified, nonconsent. Descriptive analyses revealed that use of the diagnosis, which occurred almost exclusively in adult sexually violent predator cases, increased substantially over the past decade, with cases in 3 states accounting for over $2 / 3$ of the total observed prevalence rate. In the majority of cases examined in detail, the support that evaluators relied upon in making the diagnosis was either not clearly described or behaviorally inferential in nature, and the diagnosis was often accompanied by other mental and personality disorder diagnoses. An opposing expert was observed in more than half of the cases, approximately $1 / 3$ of whom noted the debate surrounding the diagnosis and nearly $2 / 3$ of whom opined that there was insufficient evidentiary support for the diagnosis in the case at bar. Finally, all courts that reached the issue of the admissibility of the diagnosis between
\end{abstract}


2008 and 2011 admitted it, and most courts also found it sufficient to support classifying an individual as a sexually violent predator.

Keywords: paraphilia not otherwise specified nonconsent, NOS, sexually violent predator, forensic evaluation, admissibility and sufficiency of evidence

Opposing opinions have been published in recent years regarding the scientific reliability and validity of paraphilia diagnoses as applied to legally relevant questions, as well as the normative, ethical, and legal consequences of their use for such purposes. One of the most contentious debates has centered on the diagnostic construct of paraphilia not otherwise specified, nonconsent (PNOSN). Before delving into the disputes surrounding these diagnoses, however, some context is necessary. We thus begin with a brief overview of sexually violent predator laws, the psycholegal domain for which paraphilia diagnoses are most relevant.

\section{Sexually Violent Predator (SVP) Laws as Context}

SVP laws are a modern revival of earlier mentally disordered sex offender statutes (Melton et al., 2007; Slobogin, Rai, \& Reisner, 2009; Winick, 1998). The precursor sexual psychopath and sex offender statutes first appeared in the late 1930s (Melton et al., 2007). Predicated on the dual rationales of indeterminate preventative confinement and rehabilitation, these laws had been enacted by more than half of U.S. states by the time they experienced a period of repeal in the 1970s and 1980s after, inter alia, being heavily criticized by major professional organizations (Melton et al., 2007; Wettstein, 1992). Beginning in the 1990s, legislative findings that standard commitment statutes were too narrow to deal with the problem of the SVP construct (i.e., an oftentimes nonpsychotic but seemingly disturbed sexually violent recidivist), particularly with respect to the types of disorders that would satisfy the mental illness requirement for civil confinement (see Slobogin et al., 2009), beget a revival of specialty sex offender commitment statutes (see, e.g., Kansas v. Hendricks, 1997). According to some states, regular civil commitment statutes (i.e., of the non-sex-offender variety) proved insufficient for capturing the many sexual offenders diagnosed with antisocial personality disorder or a paraphilia disorder, rather than the psychotic or mood disorders more commonly associated with standard civil commitment (e.g., Kan. Stat. Ann. \$59-29a01 [2013]), as discussed in Kansas v. Hendricks, 1997). SVP statutes were enacted to fill this gap.

As of 2013, 22 states, Washington, D.C., and the federal government have laws providing for the legal and social control of those deemed to be SVPs (Lave \& McCrary, 2011; Murphy, Galloway, DeMatteo, \& Krauss, 2013). Although some variations exist among jurisdictions (e.g., Louisiana's SVP designation pertains to registration, community notification, and community supervision requirements; and Ohio's reflects a sentencing aggravator), SVP laws generally permit indeterminate civil commitment of sexual offenders after they have completed their sentences if they were (a) convicted of a sexually assaultive 
offense and (b) suffer from a mental disorder/abnormality that (c) causes volitional impairment and thereby (d) increases sexual recidivism risk (La. Rev. Stat. Ann. §15:560 et seq., 2013; Ohio Rev. Code Ann. § 2971 et seq. [West, 2013]; Witt \& Conroy, 2009).

Laws defining and regulating SVPs have survived numerous constitutional challenges at the level of the Supreme Court of the United States (SCOTUS). In Kansas v. Hendricks (1997), SCOTUS upheld Kansas's SVP law in the face of substantive due process, double jeopardy, and ex post facto challenges, reasoning that the "mental abnormality" prong of the law sufficiently limited confinement eligibility to those who cannot control their dangerousness, and that the law was civil and nonpunitive in nature. SCOTUS went on to reject a narrower punitive-as-applied challenge on double jeopardy and ex post facto grounds 4 years later in Seling v. Young (2001). Next, in Kansas v. Crane (2002), SCOTUS held that although there existed no requirement of a total or complete lack of volitional control, there must be proof of serious difficulty in controlling behavior to satisfy substantive due process requirements. Most recently, in United States v. Comstock (2010), SCOTUS upheld the federal SVP commitment scheme pursuant to the Necessary and Proper Clause in the face of a challenge that the law fell outside the scope of Congress' enumerated powers. Notwithstanding SCOTUS's approval of these laws, they are the subjects of much ongoing debate, with arguments pertaining to the nature of punishment, the proper roles of preventative detention versus rehabilitation, the correctness of SCOTUS's constitutional analyses, and the practical consequences of SCOTUS's holdings (Carlsmith, Monahan, \& Evans, 2007; Fanniff, Otto, \& Petrila, 2010; Lave, 2011; Petrila, 2008).

\section{Paraphilia Disorders and PNOSN}

Paraphilias are the most prevalent diagnostic category in SVP commitment cases (see Becker, Stinson, Tromp, \& Messer, 2003; Janus \& Walbek, 2000; Levenson, 2004; Levenson \& Morin, 2006; McLawsen, Scalora, \& Darrow, 2012), submitted in relation to the mental disorder/abnormality prong of SVP statutes. However, concerns have been raised about paraphilia disorders as a class (Miller, Amenta, \& Conroy, 2005; O'Donohue, Regev, \& Hagstrom, 2000; Schopp, Pearce, \& Scalora, 1998; Schopp, Scalora, \& Pearce, 1999), including that paraphilias have been historically understudied and are plagued by assessment difficulties, such as the unreliability of self-report information from an individual facing indefinite civil commitment. The ambiguous wording of the Diagnostic and Statistical Manual of Mental Disorders (4th ed., text rev.; DSM-IV-TR; American Psychiatric Association, 2000) paraphilia criteria also raises the possibility that a paraphilia diagnosis can function as a mere behavioral descriptor, which may not effectively discriminate individuals on the basis of pathology (i.e., distinguish between disturbed and nondisturbed recidivist rapists). The recently released fifth edition of the DSM (DSM-5; American Psychiatric Association, 2013) did not clarify this ambiguity, reflecting only a restyling of imprecise diagnostic language in substituting "sexual interest" and "paraphilic sexual fantasies, urges, or behaviors" for "sexually arousing fantasies, sexual urges, or behaviors," and "anomalous target preferences . . . includ[ing] one directed at other humans . . . and two directed elsewhere" and "other than ... phenotypically normal, physically mature, consenting human partners" for "1) nonhuman objects ... and 3) children or other nonconsenting persons" 
(American Psychiatric Association, 2000, p. 566; American Psychiatric Association, 2013, pp. 685-686). (Discussion of the DSM-IV-TR throughout this manuscript thus applies with equal force to the DSM-5.) Some also argue that paraphilia disorders, being nonpsychotic disorders, are insufficient to justify civil commitment because they do not include a substantial impairment of orientation, reality, reasoning, or comprehension necessary to justify restrictions of liberty.

Debates have additionally centered on specific paraphilia diagnoses, including a particularly pronounced debate over the diagnosis of PNOSN. PNOSN is one of the most commonly observed paraphilia diagnoses in SVP cases (e.g., McLawsen et al., 2012). It is derived from an interpretation of language in the DSM-IV-TR; specifically, Criteria A and $\mathrm{B}$ for paraphilia-class diagnoses in conjunction with Diagnostic Code 302.9 for paraphilias not otherwise specified. In contrast to the explicit V codes in the DSMIV-TR (American Psychiatric Association, 2000) and DSM-5 (American Psychiatric Association, 2013) that cover the nonpathological sexual abuse of an adult (V61.12 and V62.83), PNOSN is meant to denote a condition involving a particularly intense and persistent interest in nonconsensual or coercive sexual activity (a paraphilia) that results in distress or consequences for the individual, or actual or risk of harm to another (raising it to the level of a paraphilic disorder). The condition must also be distinguished from sexual sadism before it can be diagnosed. Doren (2002) offers a popular list of diagnostic indicators for PNOSN.

Some proponents have also suggested that the DSM-5 (American Psychiatric Association, 2013) should include an explicit paraphilic coercive disorder to offer evaluators a more clearly defined diagnosis for the nebulous construct some have used to explain certain research findings (Stern, 2010; Thornton, 2009). This proposal was not adopted. The $D S M-5$ has possibly added further complication, however, by breaking up the paraphilia not otherwise specified (Diagnostic Code 302.9) diagnosis into other specified paraphilic disorder (Diagnostic Code 302.89) and unspecified paraphilic disorder (Diagnostic Code 302.9). Other specified paraphilic disorder is essentially analogous to paraphilia not otherwise specified, whereas unspecified paraphilic disorder requires no specification by the clinician as to why the paraphilia criteria are not met for a specific paraphilic disorder. Unspecified paraphilic disorder can also be used in situations in which there is insufficient information to make a more specific diagnosis. As of January 1, 2014, no published cases could be found that referenced either diagnosis.

As a summary of the debate over PNOSN (see "DSM-5 and the Paraphilias," n.d., and "DSM-5 Paraphilias Bibliography," n.d., for comprehensive listings of primary references), arguments offered by proponents of the diagnosis (DeClue, 2006; Doren, 2002, 2006; Stern, 2010, 2011; Thornton, 2009) include the following:

- The existence of individuals with coercive or nonconsenting paraphilic interests is buttressed by clinical experience, a DSM-IV-TR Casebook example (Spitzer, Gibbon, Skodol, Williams, \& First, 2002; but see Zander, 2005), and a few study results.

- DSM-IV-TR (American Psychiatric Association, 2000) taxonomy/criteria coexist with the $D S M-I V-T R$ 's allowance for clinical judgment.

- $\quad D S M-I V-T R$ diagnostic criteria are merely guidelines. 
- SVP statutes do not require diagnoses that comport with the DSM-IV-TR.

Arguments by critics (Frances, Sreenivasan, \& Weinberger, 2008; Knight, 2010; Miller et al., 2005; Prentky, Coward, \& Gabriel, 2008; Wollert, 2011; Zander, 2005, 2008), on the other hand, include the following:

- A proposed paraphilic coercive disorder, indistinguishable from PNOSN, was explicitly rejected from inclusion in the DSM-III (American Psychiatric Association, 1980) and DSM-III-R (American Psychiatric Association, 1987), and now also the DSM-5 (American Psychiatric Association, 2013).

- The ambiguity presented by the wording of the DSM-IV-TR (American Psychiatric Association, 2000) paraphilia criteria was a mistake admitted by the chair of the $D S M-I V$ Task Force (Allen Frances), and the editor of text and criteria for DSM-IV (American Psychiatric Association, 1994), and editor and co-chair of the DSM-IVTR (Michael First; Frances \& First, 2011). The diagnosis should not function as a mere behavioral descriptor; more is required to establish the requisite deviant sexual interest and arousal pattern (i.e., sexual interest in a lack of consent per se).

- Defined paraphilias have demonstrated poor reliability, and thus even poorer reliability can be expected for the vaguely defined PNOSN.

- Adherence to explicit DSM-IV-TR diagnostic criteria fosters clearer communication and greater reliability.

- There are DSM-IV-TR codes that cast sexual abuse of an adult as a problem that is not a mental disorder but that may be a focus of clinical attention.

- Evaluators are unknowingly exhibiting the confirmation bias-rather than gathering clinical data and then drawing a conclusion, evaluators are actually making conclusions that an individual has PNOSN based on his sexual offense conviction or convictions, and then looking for clinical data to support that conclusion.

- Not-otherwise-specified (NOS) diagnoses are considered wastebasket diagnoses by some and are thus inappropriate for the forensic setting.

- There are too few studies supporting the construct and too many outstanding issues with it at present to permit its use to restrict individuals' liberty.

In sum, critics have charged that PNOSN is often a "diagnosis of convenience" or proxy for rape that frequently represents "bad faith, bad science, and ... bad clinical judgment" (Prentky et al., 2008, p. 456) - the result of which is the weakly justified incapacitation of sex offenders who have already served their sentences. Nevertheless, many critics concede that the diagnosis is conceivable, at least in theory, in exceptional cases. For instance, to support a diagnosis of PNOSN, First and Halon (2008) suggest utilizing diagnostic interviews that include questions about thoughts, urges, and behaviors with respect to paraphilic and nonparaphilic targets; employing self-report questionnaires that provide systematic assessments of sexual deviance; and ascertaining a history of specific sexual 
behaviors beyond the criminal history. This approach may guard against an excessive reliance on criminal history information, but it may be idealistic, as there exist few, if any, standardized, reliable, and valid assessment procedures for the diagnosis of sexual disorders (Akerman \& Beech, 2012; Hanson, 2010; Miller et al., 2005; Stinson \& Becker, 2008). It also does not address the critical issue of the presumptive base rate of the diagnosis. There is little evidence of what the base rate for PNOSN is, other than anecdotal accounts suggesting that it is very rare. Wollert $(2007,2011)$ reported an estimated prevalence rate among former prisoners of $5 \%$ based on estimates offered by surveyed sex offender treatment providers. The seeming rarity of PNOSN raises at least two fundamentally important questions: (a) What degree of predictive accuracy can be expected for a diagnosis that applies only in exceptional cases? (b) Does the observed frequency of PNOSN diagnoses in SVP cases comport with its theoretical rarity?

A cursory search of case law reveals that courts are in fact encountering challenges to PNOSN diagnoses, with defense experts testifying as to many of the arguments critical of the diagnosis noted above (e.g., Brown v. Watters, 2010; Commonwealth v. Dengler, 2005; In re Tripodes, 2011). But exactly when the diagnosis first occurred in court cases, and its rate of use over time, remains unknown. Instead, evidence regarding the frequency with which PNOSN has been proffered for forensic purposes has been limited to single-jurisdiction clinical data sets describing the diagnostic profiles of individuals who have been classified as SVPs. The rate of PNOSN diagnoses within these samples has ranged from approximately $14 \%$ to $43 \%$ (Boccaccini, Turner, \& Murrie, 2008 [as cited in Jumper, Babula, \& Casbon, 2012]: Texas $=21.2 \%$; Elwood, Doren, $\&$ Thornton, 2010: Wisconsin $=21.2 \%$; Jackson \& Richards, 2007: Washington $=42.6 \%$; Jumper et al., 2012: Illinois $=30.8 \%$; McLawsen et al., 2012: Nebraska $=14.2 \%)$. When the aforementioned case references and PNOSN prevalence rates among SVP detainees are taken together, it becomes clear that the debate over forensic uses of PNOSN is tied to significant real-world decision making and consequences for individuals. Courts are currently finding themselves having to wrestle with the debate to resolve cases before them, and individuals are being preventatively and indefinitely detained partially on the basis of having been diagnosed with PNOSN. Empirical legal research surveying the legal contexts in which the diagnosis has arisen, and examining specific issues that have been raised in the psycholegal literature, has the potential to add to, and bridge, what is known about the psychological and legal dimensions of the debate.

Accordingly, the purpose of the present study was to examine the forensic use of the PNOSN diagnosis by way of published legal opinions. Using all cases in which the diagnosis was cited, we first examined the jurisdictions in which it was proffered and whether the frequency of its use increased over time. We then conducted detailed reviews of a subset of the more recent cases in which the diagnosis was mentioned to examine more specific research questions. These questions pertained to the nature of the cases and the parties involved, how experts had arrived at the diagnosis, whether any opposing experts had reached different diagnoses or challenged the diagnosis, and whether courts were receptive to the diagnosis. 


\section{Method}

\section{Procedure}

We utilized a case-law-analysis methodology adapted from previous studies (DeMatteo \& Edens, 2006; DeMatteo et al., 2013; Lloyd, Clark, \& Forth, 2010; Viljoen, MacDougall, Gagnon, \& Douglas, 2010; Walsh \& Walsh, 2006). A non-time-limited search for instances of the PNOSN diagnosis in court opinions was conducted in the ALLCASES database in Westlaw. The ALLCASES database contains U.S. case law (i.e., a decision or order, including unpublished and unreported cases that typically have no precedential value) from federal, state, territorial, and military courts compiled by West. Coverage begins in 1658 and includes case law published in West reporters and other sources (for more about scope, see "Westlaw Database Directory," 2013; for more about case law research generally, see Olson (2009)). The following Terms and Connectors search string was used: paraphilia /5 nos "n.o.s." "not otherwise specified" /5 "nonconsent!" "nonconsent!"

Duplicate opinions were removed from the compiled data set of returned cases. Multiple opinions involving the same individual at different stages of appeal or review were handled differently for analyses conducted with the entire sample versus those conducted with a subsample of opinions from 2008 to 2011. For the general descriptive statistics for the full sample (i.e., jurisdiction and year frequency), we coded the first opinion that mentioned the diagnosis when there were multiple opinions pertaining to the same individual. In contrast, for the more extensively coded subsample of cases from 2008 to 2011, we relied on the most recent opinion that was sufficiently detailed to allow coding of study variables. In three instances we used a case that was not the most recent because the most recent was a short opinion such as a habeas corpus petition (i.e., a claim that one is being unlawfully detained). An earlier, more informative opinion was substituted in these instances.

Frequencies for jurisdiction and year were ascertained using WestlawNext search filters to sort all returned opinions by jurisdiction and date of publication. The first author conducted these sorting operations, coded the frequencies, and adjusted these figures to account for duplicate opinions and multiple opinions involving the same individual. Next, the first and second authors coded all of the opinions issued between 2008 and 2011 using a codebook developed by the first author based on his experience pilot reviewing some of the opinions (see Table 1 for a list of variables; the coding book is available from the first author). Each of the two authors coded approximately half of this subsample, and their data was combined into a single data set. To estimate interrater reliability, the first and second authors overlapped on 25 randomly selected cases (20\% of the 126-opinions subsample). The percentage agreement (Stemler, 2004; Uebersax, 2009) for all variables ranged from $64 \%$ to $100 \%$ and was $81.3 \%$ overall for those variables below $100 \%$ agreement (see Table 1). All discrepancies in the 25 overlap cases were reviewed and resolved by consensus between the first and second authors. In addition, for variables with a percentage agreement below $90 \%$ (i.e., below an excellent level of observed agreement; Cicchetti, 2001; Graham, Milanowski, \& Miller, 2012), the first author reviewed coding decisions for each of the 126 cases in the subsample, and sent final coding recommendations (along with associated explanations) to the second author for approval. If the second author disagreed with one of these recommendations, final consensus-based coding decisions were achieved 
via discussion between the first and second authors. The variable pertaining to whether an opposing expert referenced the PNOSN controversy was also reviewed if it or the variable pertaining to the presence of an opposing expert were endorsed in the affirmative. To handle missing data, pairwise deletion was used when calculating descriptive statistics (i.e., only when a case was missing data for the variable being analyzed was it omitted from that analysis).

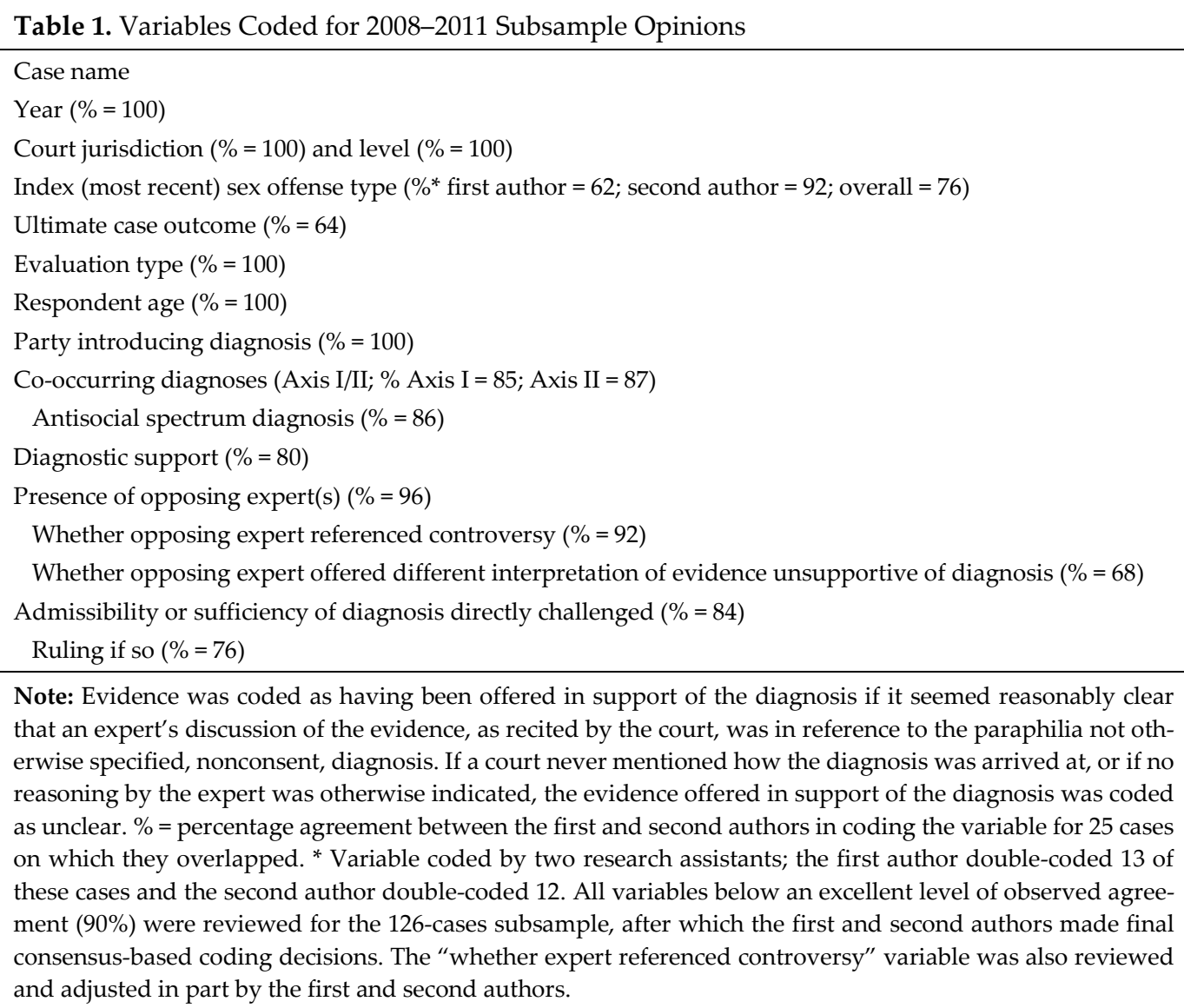

\section{Sample}

As of January 1, 2012, 237 cases were returned using our search strategy. After duplicate opinions were removed and multiple cases involving the same individual were addressed using the aforementioned procedures, 199 opinions remained for jurisdiction and year analyses, and a subsample of 127 opinions for more extensive coding. One additional case was removed from the subsample because it did not involve a respondent who had been diagnosed with PNOSN; rather, an evaluator in the case remarked that the diagnosis had been ruled out (In re Civil Commitment of J.B., June 2, 2010). The majority of the opinions in the 126-case subsample were authored by intermediate courts of appeal in each jurisdiction $(103 ; 81.7 \%)$, followed by the highest appellate court in a jurisdiction $(10 ; 7.9 \%)$ and the jurisdiction's trial courts $(5 ; 4.0 \%)$. The remaining eight cases $(6.3 \%)$ were habeas corpus 
proceedings before a federal district or circuit court. Because some opinions did not provide sufficient information to allow for all variables to be coded, results for some variables reflect the exclusion of up to eight cases.

\section{Results}

\section{Full Sample Analyses}

Year frequency

Figure 1 depicts the frequency with which PNOSN was first mentioned in a published opinion (vs. when it was actually diagnosed or proffered to a trial court) over time.

The frequency with which the diagnosis appeared in court opinions steadily increased over roughly a decade, from once in 1998, to nine and 17 times in 2005 and 2006, respectively, to approximately 30 times in 2009 through 2011. The linear relationship between year and PNOSN frequency was $r(197)=0.90, p<.01$. A visual inspection of Figure 1 reveals relative spikes in usage in 2002, 2006, 2007, and 2009.

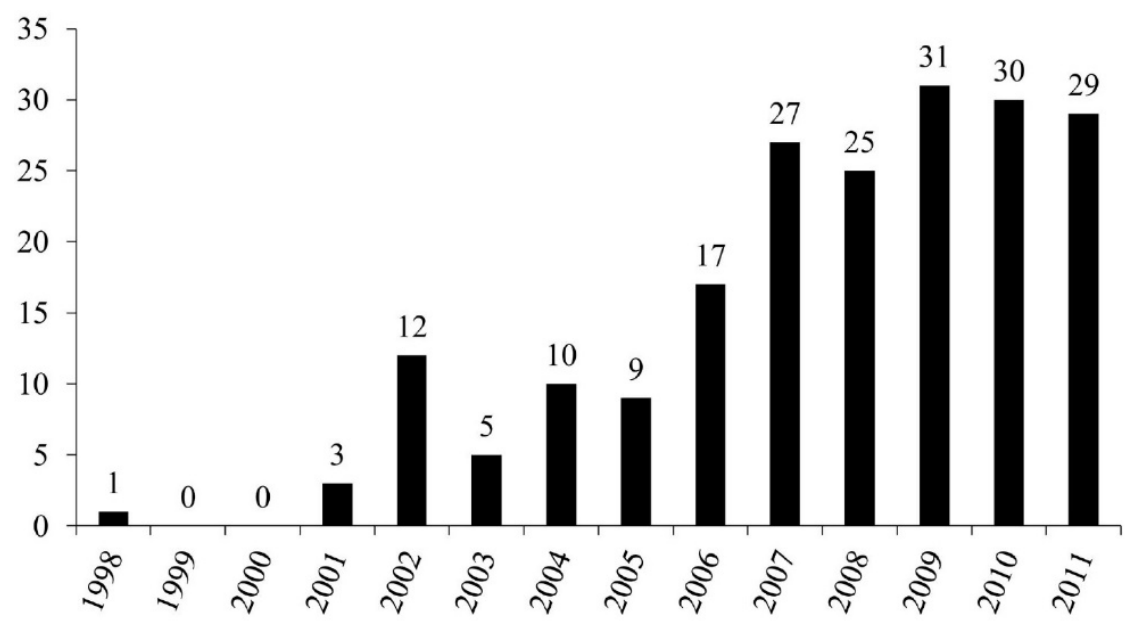

Figure 1. Frequency count of when PNOSN diagnosis first appeared in a reported legal case, by year (from first identified use through 2011).

\section{Jurisdiction frequency}

As depicted in Table 2, our search revealed 19 jurisdictions in which the diagnosis had been proffered by forensic mental health evaluators - the federal system and 18 states. The majority of cases stemmed from New Jersey, California, and Washington. Together, these three states accounted for more than two thirds of the opinions in which the diagnosis was observed. 


\begin{tabular}{lcc}
\hline \multicolumn{2}{c}{ Table 2. Frequency of PNOSN in Different Jurisdictions' Court Opinions } \\
\hline Jurisdiction & Frequency & $\%$ \\
\hline Federal & 11 & 5.5 \\
Arizona & 3 & 1.5 \\
Arkansas & 1 & 0.5 \\
California & 48 & 24.1 \\
Florida & 5 & 2.5 \\
Illinois & 7 & 3.5 \\
Iowa & 1 & 0.5 \\
Massachusetts & 2 & 1.0 \\
Minnesota & 4 & 2.0 \\
Missouri & 1 & 0.5 \\
Nebraska & 2 & 1.0 \\
New Jersey & 57 & 28.6 \\
New York & 1 & 0.5 \\
North Dakota & 5 & 2.5 \\
Pennsylvania & 2 & 1.0 \\
Texas & 5 & 2.5 \\
Virginia & 2 & 1.0 \\
Washington & 35 & 17.6 \\
Wisconsin & 7 & 3.5 \\
CA + NJ + WA & 140 & 70.3 \\
\hline Not PNOSN & &
\end{tabular}

Note: PNOSN $=$ paraphilia not otherwise specified, nonconsent; $\mathrm{CA}=$ California; $\mathrm{NJ}=$ New Jersey; WA = Washington

Because virtually all of the cases in which the diagnosis was proffered involved the application of SVP laws, we also compared our year frequency data with data by Lave and McCrary (2011) reporting the number of individuals committed or classified as SVPs by state in 2006 or 2008. This enabled a comparison between forensic PNOSN occurrences in a given jurisdiction with the number of individuals designated as SVPs in that jurisdiction. The ratio we utilized was PNOSN:SVP, with PNOSN defined as the total number of cases in our sample from a single jurisdiction divided by the total number of cases in our sample, and SVP defined as the number of SVPs in a single state divided by the total number of SVPs in all states with SVP laws. Table 3 depicts these comparisons, with Lave and McCrary's data presented in brackets. Note that Lave and McCrary were unable to ascertain the number of persons classified as SVPs in the federal system (the federal government failed to respond to their inquiry), and so this comparison is absent from Table 3.

California's large proportional contribution to the nationwide number of SVPs (23.7\%) closely resembled the percentage of California cases in our sample (25.7\%). In contrast, disproportionate ratios were observed for New Jersey (rate of New Jersey cases in our sample > rate of New Jersey SVPs reflected in the national tally of SVPs), Washington (PNOSN > SVP), Minnesota (PNOSN < SVP), and Wisconsin (PNOSN < SVP). In other words, whereas the rate of California cases in our sample of PNOSN cases was as one would expect based on the number of SVPs California contributes to the nationwide number of SVPs, we observed more cases from New Jersey and Washington in our sample than would be expected based on this metric, and fewer from Minnesota and Wisconsin. 


\begin{tabular}{lcc}
\hline \multicolumn{3}{l}{ Table 3. Frequency of PNOSN in States' Judicial Opinions Compared to States' Numbers of SVPs } \\
\hline State & Frequency & $\%$ \\
\hline Arizona & $3[58]$ & $1.6[1.7]$ \\
California & $48[808]$ & $25.7[23.7]$ \\
Florida & $5[240]$ & $2.7[7.0]$ \\
Illinois & $7[224]$ & $3.7[6.6]$ \\
Iowa & $1[75]$ & $0.5[2.2]$ \\
Massachusetts & $2[105]$ & $1.1[3.1]$ \\
Minnesota & $4[516]$ & $2.1[15.1]$ \\
Missouri & $1[110]$ & $0.5[3.2]$ \\
Nebraska & $2[10]$ & $1.1[0.3]$ \\
New Jersey & $57[340]$ & $30.5[10.0]$ \\
New York & $1[52]$ & $0.5[1.5]$ \\
North Dakota & $5[58]$ & $2.7[1.7]$ \\
Pennsylvania & $2[9]$ & $1.1[0.3]$ \\
Texas & $5[99]$ & $2.7[2.9]$ \\
Virginia & $2[138]$ & $1.1[4.1]$ \\
Washington & $35[213]$ & $18.7[6.3]$ \\
Wisconsin & $7[352]$ & $3.7[10.3]$ \\
\hline
\end{tabular}

Note: Lave and McCrary's (2011) data, which reflect states' SVP counts as of 2006 or 2008, are presented in brackets. Other SVP states reported by Lave and McCrary are Kansas (216, 5.8\%), New Hampshire (0,0\%), and South Carolina (94, 2.5\%). They did not report data for Washington, D.C., which allows for civil commitment of "sexual psychopath[s]" (D.C. Code $\$ \S 22-3803$ to -3811, 2013). Arkansas is a non-SVP state; the Arkansas case we identified pertained to a hearing regarding the appropriate extent of community notification for a convicted sexual offender. The PNOSN frequency-by-state percentages differ from Table 2 because percentages were recalculated after federal cases were removed, as Lave and McCrary did not report federal data. PSOSN = paraphilia not otherwise specified, nonconsent; SVP = sexually violent predator.

\section{8-2011 Subsample Analyses}

\section{Evaluation context and characteristics}

With respect to the evaluative contexts giving rise to the diagnosis, all but one of the 126 cases decided between 2008 and 2011 pertained to SVP commitment hearings (the one outlier case involved a determination about the appropriate level of community notification for a sex offender convicted in Arkansas; Parkman v. Sex Offender Screening and Risk Assessment Committee, 2009). We observed no attempts to use the diagnosis to excuse conduct (e.g., as an insanity defense), and in only one case did a defense expert make the PNOSN diagnosis without a state expert also diagnosing it (In re Rush, 2009). All 126 cases involved adult respondents, ${ }^{1}$ although two cases involved individuals who were initially detained as juveniles, classified as SVPs as young adults prior to their release, and eventually diagnosed with PNOSN (In re A.M., 2010; In re R.Y., Jr., 2008). Forty-two respondents (33.3\% of 126) had an adult physical sex offense as the index sex offense that gave rise to the SVP proceedings (e.g., rape of an adult), whereas $31(24.6 \%)$ had a child physical sex offense (e.g., molestation of a child) and six (4.8\%) had a nonphysical adult or child sex offense (e.g., indecent exposure, possession of child pornography). In 13 opinions (10.3\%) the index offense was unclear because the respondent's most recent conviction or arrest included both adult and child sex offenses, and in 34 cases (27.0\%), the opinion was unclear as to index offense because there either was no clear indication of the most recent conviction or 
arrest, or the opinion used a term like "sexual assault" without specifying the age of the victim.

Accompanying mental and personality disorders were commonly mentioned, present in $80(67.2 \%)$ and $105(88.2 \%)$ of the 120 cases, respectively, that reported sufficient diagnostic information. Co-occurring paraphilia disorders, personality disorders (especially personality disorder NOS and antisocial personality disorder), and substance use disorders were the most commonly reported, followed by mental retardation and psychotic disorders. Sixty-eight of 118 cases (57.6\%) included mention of an accompanying diagnosis of antisocial personality disorder, and 31 (26.3\%) indicated a co-occurring diagnosis of psychopathy or antisocial traits/features. Among respondents who most recently committed an adult physical sex offense, 37 (88.1\% of 42$)$ received a concomitant antisocial-spectrum diagnosis (i.e., antisocial personality disorder, psychopathy, or antisocial traits/features), whereas $24(80.0 \%$ of 30$)$ of those with an index child physical sex offense received such a diagnosis, $\chi^{2}(1, N=72)=.89, p=.35, \varphi=-0.11$.

Table 4 lists what could be gleaned of the evidentiary sources relied upon by evaluators in arriving at a PNOSN diagnosis. Although the evidentiary bases for the diagnosis were unascertainable in the majority of cases (69 of 122; 56.6\%), the discussions in numerous opinions (30; $24.6 \%)$ suggested that an evaluator had relied exclusively on past-behavior reasoning (most often the fact that the respondent had repeatedly engaged in nonconsensual sexual conduct). The next most commonly referenced diagnostic evidence was a respondent's own statements (e.g., the respondent reported something to the effect of "I could not control my sexual impulses," or the expert reviewed notes or letters written by the respondent), reportedly relied upon in support of the diagnosis in $20(16.4 \%)$ cases. We note that statements akin to "I could not control my sexual impulses" bear chiefly upon the distinct issue of volitional impairment. Without additional statements indicating that such sexual impulses specifically pertain to sexual interests in nonconsenting victims, they are irrelevant to the issue of anomalous target preferences. In this way, such statements are analogous to conditional relevance in the law of evidence (e.g., Fed. R. Evid. 104(b)).

\begin{tabular}{lcc}
\hline Table 4. PNOSN Diagnostic Bases & & \\
\hline Evidentiary source & Frequency & Percent \\
\hline Explicit behavior-based reasoning & 30 & 24.6 \\
Physiological testing & 2 & 1.6 \\
Respondent's statements & 20 & 16.4 \\
Physiological testing + respondent's statements & 1 & 0.8 \\
Unclear & 69 & 56.6 \\
Total & 122 & 100.0 \\
\hline
\end{tabular}

Note: Diagnostic bases were conceptualized as evidentiary sources that an evaluator explicitly linked to diagnostic criteria for PNOSN. As an example of our specific operationalization, for past behavioral evidence, if an evaluator specifically referenced instances of past behavior and provided a clear explanation tying the prior behavior to the diagnostic criteria for PNOSN, this was counted as explicit behavior-based reasoning, regardless of the validity of the reasoning. But global statements lacking any explication, such as "criminal history supports the diagnosis," were coded as unclear. There were no incidents of psychometric testing by an expert who diagnosed PNOSN. Four cases did not report sufficient information for this variable to be coded. PSOSN $=$ paraphilia not otherwise specified, nonconsent. 
Judicial mention of an expert's use of physiological testing (e.g., penile plethysmography, visual reaction time, and polygraph) was observed on two occasions (1.6\%). Psychometric testing (i.e., self-report measures of sexual interest and arousal; not risk assessment instruments or general personality measures) by an expert who diagnosed PNOSN did not occur in our sample (compared with experts who did not diagnose PNOSN; see, e.g., People v. Orozco, 2008). A report than an expert utilized some combination of the various assessment techniques was only observed once $(0.8 \%)$, although reliance upon historical behavioral evidence could reasonably be assumed in all cases.

The presence of an expert retained by the respondent was observed in 73 of 119 cases (61.3\%). Experts noted the controversy surrounding the PNOSN diagnosis in 23 of 70 of these cases $(32.9 \%)$. Alternatively or additionally, a respondent-retained expert opined either explicitly or implicitly that his or her evaluation did not support a diagnosis of PNOSN in 49 of 67 of these cases (73.1\%). Note that this last variable was coded to include both explicit statements of disagreement by an expert about the presence of PNOSN, as well as the situation in which an opposing expert simply did not diagnose it and offered other or no diagnoses instead.

\section{Case outcomes}

Table 5 reveals that the majority (97 of 126; 77.0\%) of opinions from 2008 to 2011 did not involve a direct challenge to the validity of the PNOSN diagnosis, and thus the deciding courts had no occasion to opine on either the admissibility of the diagnosis or its sufficiency in the case at hand. There were also a number of courts $(13 ; 10.3 \%)$ that were able to avoid resolving a challenge to the diagnosis by disposing of a case on other grounds, typically for procedural or pleading defects (e.g., failing to object at trial). In one outlier case that actually did not involve a challenge to the diagnosis by the respondent, the state's expert nevertheless rescinded his PNOSN diagnosis after he independently learned of the controversy surrounding it (In re Richard K., 2010). All 16 courts that reached a challenge to PNOSN's admissibility found it to be admissible. However, after admitting evidence about the diagnosis, two courts were still insufficiently persuaded that the state had met its burden in proving the diagnosis's applicability to the particular respondent at issue (People $v$. C.M., 2009; United States v. Graham, 2010).

Table 5. Disposition of Challenges to Admissibility or Sufficiency of PNOSN

\begin{tabular}{lcc}
\hline Holding & Frequency & Percent \\
\hline Held admissible and sufficient & $14(87.5 \%)$ & 11.1 \\
Held admissible but insufficient & $2(12.5 \%)$ & 1.6 \\
Other & 13 & 10.3 \\
Challenge not raised & 97 & 77.0 \\
Total & 126 & 100.0 \\
\hline
\end{tabular}

Note: The "Other" category entailed cases in which courts avoided deciding upon challenges to PNOSN for procedural or unclear reasons. PSOSN = paraphilia not otherwise specified, nonconsent 
Table 6 depicts the ultimate outcomes of the cases from 2008 to 2011 that were examined in detail. The majority of these cases $(76$ of $126 ; 60.3 \%$ ) resulted in an individual being classified as an SVP, or a prior SVP classification being affirmed. Courts also frequently upheld the sufficiency of the state's evidence but ultimately disposed of a case on different grounds $(40 ; 31.8 \%)$. In contrast, only two cases $(1.6 \%)$ resulted in an individual not being classified as an SVP (People v. C.M., 2009; United States v. Graham, 2010). The remaining cases were disposed of without the court opining on the issue of the sufficiency of the evidence $(8 ; 6.3 \%)$.

\begin{tabular}{lcc}
\hline Table 6. Ultimate Case Outcome & & \\
\hline Outcome & Frequency & Percent \\
\hline SVP classification made & 1 & 0.8 \\
SVP classification affirmed & 75 & 59.5 \\
SVP classification not made & 2 & 1.6 \\
Case affirmed for other reasons & 23 & 18.3 \\
Case reversed for other reasons & 10 & 7.9 \\
Case dismissed for other reasons & 7 & 5.6 \\
Other & 8 & 6.3 \\
Total & 126 & 100.0 \\
\hline
\end{tabular}

Note: Cases that were disposed "for other reasons" were those in which a court made a ruling on the sufficiency of the evidence but ultimately disposed of the case on some other basis. "Other" dispositions included remands for new trials (including new determinations of evidentiary sufficiency), stays, etc. SVP = sexually violent predator

\section{Discussion}

In examining variables related to incidents of PNOSN in judicial opinions, the present study offers some additional context for the debate surrounding the diagnosis, and by extension, forensic paraphilia diagnoses generally. The rate at which the diagnosis has been noted in judicial opinions has steadily increased over the first decade of the 20th century, recently being mentioned in roughly 30 cases per year. Virtually all of these cases have arisen in the SVP context, and interestingly (but potentially spuriously), a hike in the frequency with which the diagnosis was observed occurred in 2002, the same year Doren's SVP evaluation text, which offered diagnostic guidance for PNOSN, was released (Frances \& First, 2011; Zander, 2005). Another spike was observed in 2007, possibly the result of greater publicity of the PNOSN debate in the professional literature around this time. Relevant to the concern that recognition of a paraphilic coercive disorder by the American Psychiatric Association might result in attempts to use the diagnosis to excuse behavior, none of the cases in our 2008 to 2011 subsample involved any attempt to use the diagnosis as the basis for a mental state defense (see, e.g., Slobogin et al., 2009).

The diagnosis was advanced most often (by far) in three states that have historically been at the center of policy developments pertaining to the legal and social control of sexual offenders (King, 2011; see also Lieb, 1996): New Jersey (introduced model community notification law in 1994 with Megan's Law, 1994 N.J. Sess. Law Serv. ch. 128 [West]; 2001 
N.J. Sess. Law Serv. ch. 167 [West]), California (adopted first ever statewide sex offender registration law in 1947), and Washington (first state to adopt sex offender community notification and modern-day SVP law, both in 1990). The frequency with which PNOSN appeared in California opinions roughly corresponded to the proportion of Californians classified as SVPs relative to the national number of SVPs. However, the frequency with which the PNOSN diagnosis arose in New Jersey and Washington cases was notably greater than both of those states' proportional contribution to the national number of individuals classified as SVPs. The situation was opposite in Minnesota (which has had a "sexual psychopathy" law on the books since 1939, and a sexually dangerous persons law since 1994) and Wisconsin (one of the earlier adopters of a SVP law back in 1994); both states' proportional contribution to the national number of individuals classified as SVPs was distinctly greater than the frequency with which the PNOSN diagnosis appeared in each state's respective judicial opinions in our sample (Lave \& McCrary, 2011; Lieb, 1996). In other words, based on the number of SVPs in each state reported by Lave and McCrary (2011), we saw more New Jersey and Washington cases in our sample than would be expected, fewer Minnesota and Wisconsin cases, and about as many California cases.

Potential explanations for these latter discrepancies include that SVP evaluators in New Jersey and Washington are more receptive to the PNOSN construct and apply it more readily than do evaluators in other jurisdictions. New Jersey and Washington both introduced landmark sex offender community notification legislation, and Washington was the first state to adopt a contemporary SVP law (see also King, 2011, for a review of the history of sex offender registration and community notification laws). Both were thus at the forefront of increased legislative and social control efforts for sex offenders. It is possible that an orientation toward aggressive sex offender policies exists in those states, felt down to the level of evaluator attitudes (see, e.g., Wettstein, 1992). Greater support for incapacitation and secure rehabilitation among regularly testifying local evaluators might, in turn, be expected to correlate with less conservative diagnostic practices (i.e., not limiting oneself to the more widely accepted diagnoses in the current version of the DSM, or the DSM system at all). Alternative explanations include that evaluators in New Jersey and Washington may be encountering a disproportionate number of individuals in the SVP context for whom a PNOSN diagnosis seems appropriate, whereas evaluators in Minnesota and Wisconsin may be seeing the opposite. It is also possible that there are more cases in which the diagnosis has been introduced in Minnesota and Wisconsin that simply have not been appealed (possibly due to procedural or proof hurdles), and thus are not reflected in our sample consisting of mostly appellate decisions.

Future research might investigate these various possibilities. Differential PNOSN rates have been reported among SVPs samples drawn from five different states (Jumper et al., 2012; McLawsen et al. 2012). The potential explanation that disproportionately larger numbers of sex offenders with PNOSN happen, by chance, to reside in certain jurisdictions (e.g., Washington and New Jersey) seems unlikely. What is perhaps more likely is that there are only a small number of experts in certain states who perform SVP evaluations and who are thus repeatedly retained in these cases. If the few experts routinely used by the state constitute proponents of the diagnosis, one would expect the overall number of cases involving the diagnosis to be inflated in the jurisdiction. That this explanation does 
not seem to apply to a state like Wisconsin, however, which, in theory, might be expected to present as a bastion of PNOSN (see author affiliations in Elwood et al., 2010), suggests a need for further research of this issue. Future investigations might sample SVP evaluators nationally and survey them about their diagnostic attitudes and practices in reference to PNOSN, with responses ultimately broken down by state (cf. Jackson \& Hess, 2007; Packard \& Levenson, 2006; Wollert, 2007). Another possibility would be to use a methodology similar to ours and code the names of PNOSN-diagnosing evaluators referred to in judicial opinions in different jurisdictions.

All of the cases that were coded in detail involved respondents who were first diagnosed with PNOSN as adults. However, as noted, two cases involved respondents who were classified as SVPs around the age of majority and who were later diagnosed with PNOSN. The Pennsylvania case of In re R.Y., Jr. (2008), for example, involved an individual who was adjudicated delinquent in 1999 for an offense committed when he was 12 years old. Upon the respondent's reaching of adulthood, the state sought to have him classified as an SVP for the purposes of involuntary confinement. He was evaluated and diagnosed with PNOSN in 2006. The facts of In re A.M. (2010) are similar.

Evaluators diagnosing PNOSN often diagnosed co-occurring disorders, particularly paraphilic (other than PNOSN), personality, and substance use disorders, in addition to mental retardation and psychotic disorders. This is largely consistent with the finding that sexual offenders often evidence multiple sexual deviances (Abel, Becker, CunninghamRathner, Mittelman, \& Rouleau, 1988), as well as other reported observations of the diagnoses assessed for, or made by, experts in SVP cases (Jackson \& Hess, 2007; McLawsen et al., 2012; Prentky, Janus, Barbaree, Schwartz, \& Kafka, 2006). In most cases, the evidentiary bases upon which evaluators predicated PNOSN diagnoses were unclear or else seemed to be largely historically and behaviorally inferential in nature, such as a repetitive history of nonconsensual sexual activity (i.e., sex offenses), sometimes coupled with perceived sexual misbehavior on the part of the respondent while he was detained. Evaluators in a few cases also interpreted statements by a respondent as being corroborative of a PNOSN diagnosis. Rare was any psychometric or physiological testing of deviant sexual interest or arousal (Akerman \& Beech, 2012; Hanson, 2010; Miller et al., 2005; Stinson \& Becker, 2008). These findings are consistent with the paramount status many experts assign to evidence rooted in an individual's history (ascertained largely by record review) in conducting SVP evaluations (Jackson \& Hess, 2007; Lanyon \& Thomas, 2008; Witt \& Conroy, 2009). Moreover, the finding that the data and reasoning foundations for evaluators' diagnostic conclusions were typically unclear is consistent with research on the most commonly observed deficiencies in forensic report writing (Grisso, 2010; Wettstein, 2005).

Regarding the high number of cases in which the PNOSN diagnostic bases were unclear, it is possible that evaluators did not impress the courts as to their reasoning, which is problematic insofar as it would suggest insufficient performance by experts with respect to case formulation and presentation. But it is also possible that judges are simply not describing experts' reasoning in court opinions. Equally concerning, courts may not find diagnostic reasoning as important as diagnostic labels, perhaps because ultimate diagnoses directly answer the legal question of whether a respondent has a mental disease, disorder, abnormality, or defect. If this were the case, obvious concerns include a labeling effect and the 
fact that not all diagnoses have been shown to be equally reliable or valid in general, or adequately reliable and valid in clinical contexts, or sufficiently reliable and valid in forensic settings. Legal fact finders who implicitly regard all diagnoses as essentially on par with one another commit an inaccurate interpretation of psychodiagnostic evidence that is biased against SVP respondents.

We also highlight the finding that in cases in which we could ascertain the evidence relied upon by an expert to diagnose PNOSN, the evidence tended to involve behavioral indicia of repetitiveness. This bears upon one of the central points of contention in the PNOSN debate. Critics of the PNOSN diagnosis argue that there is no ambiguity in the DSM-IV-TR (American Psychiatric Association, 2000) about repetitiveness alone not amounting to a paraphilia; instead, they urge that the necessary finding for a paraphilia diagnosis is an anomalous sexual interest. Otherwise, if repetitiveness were the sole inclusion criterion (e.g., three or more instances of nonconsensual sexual acts), problems arise in terms of discriminating recidivist sex offenders warranting a PNOSN diagnosis from those whom do not, or for whom an exclusive diagnosis of sexual sadism is appropriate. This argument subsumes the proposition that there is nothing anomalous about the target preferences in the vast majority of rapes, including rapes committed by recidivists. Given that proposition, what is then imperative to reach consensus about are the precise criteria that identify the exceptional offender with PNOSN from all other repeat sex offenders. Such criteria should guide evaluators as to what is anomalous about an offender's sexual interest in the target besides having ignored that a victim (or victims) did not choose to be sexual with him or her. That is, what factors suggest that a lack of consent per se was what was sexually preoccupying and motivating for the offender?

An overall upward trend in the frequency with which courts mentioned the diagnosis over time persisted, despite the emergence of the debate over the diagnosis in the professional literature-a debate that was often brought to courts' attention. An expert for the respondent was present in a majority of cases from 2008 to 2011, opining in about three fourths of such cases that his or her evaluation did not result in a diagnosis of PNOSN. The respondent raised the professional disagreement surrounding the diagnosis in about one quarter of the cases in the subsample (often in conjunction with expert testimony about the controversy), and testimony by prominent PNOSN critics was occasionally proffered. Neither of these strategies has proven particularly effective, however, as most courts have elected to assign more weight to the opinions of state experts when faced with conflicted expert testimony on the issue.

Furthermore, a court actually reaching the issue of whether PNOSN is a legitimate paraphilia was an infrequent occurrence. Given the subtly of the issue (stemming from the $D S M-I V-T R$ (American Psychiatric Association, 2000) indisputably including a NOS category) and the presentation of wrangling experts, it is perhaps expectable that courts would not typically weigh in. Unless the defense counsel cross-examining the state expert is exceptionally well versed in and aggressive about the issue, it may either not occur to a court to decide on the issue or a court may determine for various reasons that such a decision is unnecessary given the case before it. What is more probable is that the defense attorney will not even bother raising or belaboring the issue in favor of attacking other more vulnerable parts of the expert's testimony. This is all the more likely, given that $100 \%$ of the 
courts in our sample that reached the issue allowed the diagnosis into evidence, something which attorneys may implicitly or even explicitly know. Nevertheless, even after admitting the diagnosis into evidence, two courts were insufficiently persuaded that the respondent had been rightly diagnosed with PNOSN (People v. C.M., 2009; United States v. Graham, 2010), and in one case, a state expert recanted his initial PNOSN diagnosis after learning of the controversy surrounding it (In re Richard K., 2010). There is thus some justification for proffering arguments challenging the diagnosis-albeit chiefly in the interest of zealous advocacy and preserving the issue for appeal, as such arguments are rarely successful.

\section{Legal Analysis}

\section{First identified use}

The first identified case that included mention of the PNOSN diagnosis was In re State $v$. Seibert (1998), a case decided by the Court of Appeals of Wisconsin. We offer a brief synopsis of the case for historical documentation purposes. In this case, a resident of a secure mental health facility who had been previously classified as an SVP filed a petition for release that was denied by the trial court. The resident subsequently appealed on the grounds of a lack of treatability, and that the treatment that had been afforded him had been insufficiently tailored to his individual needs. He argued that the appropriate remedy under such circumstances was release. The appellate court rejected all of Seibert's contentions and affirmed the trial court's ruling.

Pertinent for present purposes was the Seibert court's discussion of the testimony delivered by two state experts, Drs. Raymond Wood and Charles Lodl. As articulated by the court,

Wood diagnosed Seibert as suffering from "paraphilia not otherwise specified nonconsent" and an antisocial personality disorder. He described "paraphilia not otherwise specified nonconsent" as meaning in Seibert's case as having, for at least six months, continued recurrent urges, arousals and fantasies for having forced nonconsensual sexual contact. Wood testified that the paraphilia affected Seibert's emotional or volitional capacity and there was a substantial probability Seibert would commit additional acts of nonconsensual sexual violence ... Lodl agreed with Wood's diagnosis. (p. 746)

The court did not mention any objections to the PNOSN diagnosis, which had earlier been accepted by the trial court, alongside the personality disorder diagnosis, as satisfying the mental disorder prong of the state's SVP statute.

Bases for holding the diagnosis to be admissible

The majority of courts that have had occasion to rule on the admissibility of the PNOSN diagnosis have deemed it minimally acceptable. Courts have generally employed three rationales to uphold the diagnosis. Under the first approach, some courts have reasoned that the PNOSN diagnosis is not so unfounded so as to violate due process outright, and 
that the fact finder can adequately factor in the disagreement among professionals in determining the degree of credibility to assign to the expert testimony (e.g., Brown v. Watters, 2010). Other courts have held that because the practice of psychological evaluation, in general, has long been entwined with the courts, and is generally deemed sound, the admissibility of each individual diagnosis does not need to be established (e.g., In re Detention of Berry, 2011). Under the final approach, some courts have construed SVP classifications as a statutory rather than wholly scientific endeavor, and have thus cast diagnoses offered in the SVP context as something apart from, and requiring less rigor than, purely clinical diagnoses (e.g., Commonwealth v. Dengler, 2005). Proffered diagnoses consequently do not need to comport with the DSM-IV-TR (American Psychiatric Association, 2000; e.g., In re Tripodes, 2011). The result under all three approaches is the same: PNOSN is deemed admissible but the fact finder is tasked with determining the credibility of the expert's PNOSN diagnosis in weighing its sufficiency (in satisfying the mental illness prong of a SVP statute) on a case-by-case basis.

The two cases in which the diagnosis was held admissible but insufficient

Two outlier courts permitted testimony on PNOSN but were not persuaded that it was sufficiently credible as applied to the respondent in each case or that the diagnosing expert witness was not sufficiently credible. In People v. C.M. (2009), the Supreme Court of Kings County, New York (Brooklyn), held the PNOSN diagnosis to be insufficient to carry an SVP classification under the factual and testimonial scenario presented to it. ("Supreme Court" in New York State designates a trial-level court; the highest court in New York State is called the "Court of Appeals.") C.M. entailed an SVP bench hearing on the issue of whether a sex offender-who had twice pled guilty to rape offenses (including one perpetrated against a minor) and been convicted of miscellaneous other nonsexual offenses, had a history of public masturbation and exposing his genitals, and had once wrote a sexually explicit letter to a female corrections officer-suffered from a mental abnormality so as to justify his involuntary confinement. The state called two expert witnesses and the respondent called one. Under New York law, it was the state's burden to prove each SVP element by clear and convincing evidence, which required more than mere reference to the fact that C.M. had been convicted of sexual offenses.

One of the state's experts in the case diagnosed C.M. with PNOSN, whereas a second state expert did not, based on a differing interpretation of factual material bearing on C.M.'s interest in the nonconsensual aspects of his sexual crimes (the second expert instead offered diagnoses of exhibitionism and personality disorder NOS). A third expert retained by C.M. did not diagnose PNOSN, as he disagreed both with the appropriateness of any NOS diagnosis in forensic settings and on relying exclusively on behavioral evidence, or inferences based on such evidence, to make a paraphilia diagnosis. All of the experts testified about the lack of consensus among mental health professionals regarding the validity of PNOSN under the DSM-IV-TR (American Psychiatric Association, 2000) and why such differences of opinion existed. Specifically, they noted the following: publications by two editors of the DSM-IV-TR (American Psychiatric Association, 2000), Drs. First and Halon, about the "error" of adding the word "behavior" to the diagnostic criteria for paraphilias; the opinion that Drs. First and Halon were classification experts, not experts in sex offender 
diagnosis and treatment; and the rejected proposal to include a nonconsent paraphilic disorder in an earlier version of the DSM, in part because of a concern that such a diagnosis would be asserted as a defense in criminal prosecutions. The first state expert and C.M.'s expert also defined "nonconsent" differently.

Legally, C.M. argued that proof of mental abnormality required a diagnosis that was limited to the specified paraphilias and personality disorders with explicit diagnostic criteria in the DSM-IV-TR (American Psychiatric Association, 2000). The state argued oppositely that no proof of any specific DSM-IV-TR diagnosis was required. Rather, the state's position was that it was sufficient under the controlling statute to establish that C.M.'s behavior was atypical and motivated by some psychiatric condition, even if poorly defined. The court rejected aspects of both parties' positions. Although it rejected the contention that a diagnosis specified by the $D S M-I V-T R$ was required for a finding of mental abnormality, the court reasoned that "at the very least, to meet its evidentiary burden, the [state] must be able to clearly define the parameters of the alleged condition or disorder" (People v. C.M., 2009, p. 5). With this logic in mind, the court reasoned,

This trial was rife with testimony that was loose, equivocal or contradictory. Even considering just that of the petitioner's two experts, the court cannot discern precisely what mental condition, disease or disorder the respondent suffers from. Nor is it clear that there is a scientifically reliable basis for either of the principal diagnoses offered by the two experts: a paraphilia based on an attraction to the victim's lack of consent or an adult-onset antisocial personality disorder. Additionally, it is not clear whether the respondent's behavior actually fit within the criteria for either proffered diagnosis, particularly where each doctor defined the necessary diagnostic criteria differently.

Without an understanding of what mental condition or disorder motivates the respondent's behavior, it is impossible to conclude that there exists a condition or disorder which predisposes the respondent to commit ... sex offenses or that would cause him difficulty in controlling such behavior. While it is clear that the respondent has committed two ... sexual offenses in the past, the trial testimony leaves the court unable to conclude that the respondent did so as a result of a mental abnormality. (People v. C.M., 2009, p. 5)

The second case in which a PNOSN diagnosis proved unpersuasive as applied to a particular respondent was United States v. Graham (2010), a federal SVP case arising in the United States District Court for the District of Massachusetts. In this case, the government sought to involuntary commit respondent before his release from federal custody for rape convictions. Graham had also been previously convicted of rape, assault with attempt to rape, driving while intoxicated, and battery, as well as various institutional infractions and violations of community supervision, in addition to miscellaneous offenses committed as a juvenile. Under federal law, it was the government's burden to prove, by clear and convincing evidence, that Graham suffered from a mental abnormality. 
A bench trial proceeded, at which the government called a single expert witness who diagnosed Graham with PNOSN and antisocial personality disorder. The government's expert supported her use of the PNOSN diagnosis by reference to an example in an older iteration of the DSM-IV-TR Casebook (Spitzer et al., 2002; but see Zander, 2005). Her analysis also proceeded by way of Doren's (2002) nine factors for evaluating PNOSN. In response to her testimony, Graham called two expert witnesses (one court-appointed and the other selected by Graham), neither of whom diagnosed him with PNOSN. The courtappointed expert did, however, diagnose Graham with antisocial personality disorder.

The government presented to the court that it sought to commit Graham based on the antisocial personality disorder diagnoses in combination with the PNOSN diagnosis, ceding that antisocial personality disorder was not sufficiently serious under the controlling federal statute to alone justify commitment. Thus, the court's decision on whether the PNOSN diagnosis had been proven clearly and convincingly would be dispositive. The court made clear at the outset that its ruling was not based on a rejection of the validity of the PNOSN in the abstract. Rather, it held that, even assuming the diagnosis to be valid, the evidence offered in support of it, as applied to Graham, was unpersuasive and thus insufficient to satisfy the mental abnormality prong of the Adam Walsh Child Protection and Safety Act (2006).

Besides the fact that the two experts retained by Graham did not diagnose him with PNOSN, the court also noted doubts it had stemming from testimony that a paraphilic coercive disorder was rejected from inclusion in the DSM-III-R (American Psychiatric Association, 1987); the base rate of paraphilias among sex offenders was low; and although PNOSN is theoretically conceivable, to deemphasize internal mental state was a radical position. The court was, moreover, critical of the government expert's reliance on the Doren (2002) criteria rather than "an explicit examination of the 'essential features' of a paraphilia" United States v. Graham (2010; p. 142) - not necessarily as provided for in the DSM system (a DSM-system diagnosis not being required under the Adam Walsh Child Protection and Safety Act, 2006), but rather as delineated by the First Circuit in United States v. Carta (2010). According to the court, its own analysis hinged on "the first 'essential feature' of a paraphilia, namely the presence or absence of recurrent, intense sexually arousing fantasies, sexual urges, or behaviors involving nonhuman objects, the suffering or humiliation of oneself or one's partner, or children or other nonconsenting persons" (United States v. Graham, 2010, p. 143). It rejected a broad reading of this language from the DSM$I V$-TR (American Psychiatric Association, 2000), reasoning that all repeat rapists would be covered under such a reading. The court also distinguished the example cited from the DSM-IV-TR Casebook (Spitzer et al., 2002), stressing the comparative dearth of evidence in the record supporting such a diagnosis for Graham versus the detailed supportive evidence described in the casebook example.

Fatal to the government's case, the court deemed the state expert to be noncredible overall. The first cited reason for this finding was because of factual inaccuracies (e.g., repeatedly referring to an "assault with intent to commit rape" as "rape") and purported inconsistencies contained in her report, as well as what the court regarded as some questionable characterizations and conclusions made on her part. The court also challenged her analysis as to some of the Doren (2002) factors. The third reason was her unwillingness to credit 
evidence weighing against a PNOSN diagnosis. Finally, the court noted that Graham's selected expert also suspected bias on the part of the state expert, taking issue with what he characterized as her default assumption of the presence of the diagnosis, and of presenting a provisional diagnosis as a "final" diagnosis. Taken together, the court found the state expert was biased in terms of being predisposed toward diagnosing PNOSN and characterizing it as serious enough to justify commitment in Graham's case. And by thus discrediting her testimony, the court held that the government had failed to meet its burden of proof with respect to establishing that Graham suffered from a mental abnormality sufficient to justify his confinement under the Adam Walsh Child Protection and Safety Act (2006).

\section{Limitations and Directions for Future Research}

It should be noted that the present study was marked by a number of limitations. Triallevel opinions are rarely published and hence infrequently reflected in online legal databases (e.g., Westlaw's ALLCASES database). As such, the prevalence of the use of the diagnosis in court is likely significantly greater than our sample of mostly appellate decisions would suggest. At the same time, however, the relatively small number of persons classified as SVPs nationally suggests that the prevalence of the diagnosis may still be relatively circumscribed, particularly because, in our sample, the diagnosis occurred virtually exclusively in SVP cases. The differentially observed PNOSN rates emanating from the different states that were reflected in our sample of cases, however, does not seem to lend itself to any clear explanation beyond the speculation we offered in this article.

Another limitation pertained to our reliance on court interpretations of mental health diagnostic testimony rather than actual forensic mental health evaluations. Such reliance required the inferential assumptions that courts correctly understood and restated mental health testimony about PNOSN and related issues, and that such restatements and discussions were sufficiently detailed to allow the variables of interest to be coded reliably and validly. The level of relevant detail encountered in our sample of court opinions was highly variable, frequently requiring inferential coding decisions to be made, notwithstanding the presence of a coding book. This undoubtedly lowers the degree of confidence with which conclusions can be drawn from our data about the evidentiary bases experts relied upon to diagnose PNOSN (and from Table 4, in particular). An examination of coding reliability revealed that percentage agreement for variables ranged from perfect to subpar, necessitating that, for some variables, all cases be reviewed by the first and second authors to improve coding reliability. Thus, coding challenges presented by the case-law study methodology is a major drawback of the approach. Although utilization of court opinions was the optimum strategy for exploring some of the legal issues surrounding the PNOSN diagnosis, future studies could afford a clearer understanding of the clinical issues obliquely examined in this study by utilizing actual mental health evaluation reports rather than one-step-removed court opinions. This would add to what has been learned from surveying mental health experts (Jackson \& Hess, 2007).

Our decision to constrain our examination to a single controversial diagnosis further limits the impact of our findings, as a number of controversial diagnoses besides PNOSN 
are also observed in sex offender contexts. Paraphilia disorders represent the most controversial diagnostic class by far, being trailed by personality disorders and substance use disorders, among others (e.g., McLawsen et al., 2012). Each controversial diagnose, of course, involves its own relatively unique set of issues. However, in recalling that PNOSN is one of the most controversial paraphilia diagnoses, the fact that it was nevertheless deemed admissible in all of our cases, and credible in most, suggests that these findings would likely generalize to the paraphilias as a class (under any one of the three legal theories previously described). We also restrained our detailed review of cases to the 20082011 timeframe. Our rationale was that by 2008, published articles on both sides of the debate were becoming more commonplace, and therefore evaluators and attorneys working in the SVP context were more likely to have been aware of the controversy by that time (and, in turn, to inform the courts of it). Although we suspect that most of the earlier opinions in our full sample involve PNOSN diagnoses that went unchallenged, due to the debate not yet having gained notoriety, whether our detailed findings extend to cases decide before 2008 remains unknown.

Finally, we did not systematically examine issues pertaining to the volitional impairment prong of SVP statutes (Fabian, 2012; Grinage, 2003; Lanyon \& Thomas, 2008; Mercado, Schopp, \& Bornstein, 2005; Winsmann, 2012; see also Morse, 1994). This was despite the fact that experts in the cases we reviewed frequently differed as to how they conceptualized volitional impairment, often prompting divergent conclusions. Although volitional impairment is presumably a distinct issue from that of anomalous sexual interest (i.e., merely having a paraphilia does not by itself establish one's inability to adequately manage sexual urges), the intersection of the two constructs is worth further investigation, given that both are necessary findings for an SVP classification. Future studies might utilize methodologies both similar and different to ours to address some of these shortcomings. Systematic case law reviews might also be used to examine other issues that have been raised about the confluence of clinical diagnoses and the application of civil and criminal law to sex offenders (Frances et al., 2008; Prentky et al., 2006; Schopp et al., 1999; Schopp \& Sturgis, 1995).

\section{Summary and Concluding Practice Recommendations}

The results of this study chiefly revealed that PNOSN has appeared with increasing regularity in reported court opinions over the past 10 years, has occurred almost exclusively in the SVP context (and always in the broader sex offender context), and has been deemed admissible by a supermajority of courts. With PNOSN being among the most controversial paraphilia diagnoses, it is reasonable to infer that the findings would generalize to the less controversial paraphilia diagnoses as well. Many mental health experts may be espousing their belief in the validity of the diagnosis through the regular use of it in sex offender civil commitment evaluations. Alternatively, the fact that many psychologists appear to be using it may have nothing to do with a personal determination that the diagnosis is scientifically valid: PNOSN may simply be employed when no better alternative diagnosis exists and one's support for commitment requires a diagnosis. To that end, courts readily admit the diagnosis regardless of whether they are persuaded that the diagnosis falls inside or outside the scope of the DSM system. 
With this state of affairs juxtaposed against the concerns, cautions, and objections from critics (Knight, 2010; Prentky et al., 2006, 2008; Wollert, 2011; Zander, 2008), standardization, reliability, and validation research of the construct would be prudent (see Quinsey, 2010). Practitioners should also subject their reasoning and potential biases to internal and external scrutiny whenever considering a diagnosis of PNOSN, given ethical guidelines that call for objectivity and transparency in forensic assessments (see Sections 10 and 11 of the Specialty Guidelines for Forensic Psychology; American Psychological Association, 2013); Section IV of the Ethics Guidelines for the Practice of Forensic Psychiatry (American Academy of Psychiatry and the Law, 2005), and recent research that has uncovered apparent partisan allegiance effects in forensic mental health evaluations (Boccaccini, Turner, Murrie, \& Rufino (2011); Murrie, Boccaccini, Johnson, \& Janke, 2008; Murrie et al., 2009; Rufino, Boccaccini, Hawes, \& Murrie, 2012). Examples of such tests of one's reasoning would include the development and use of diagnostic checklists (Witt, 2010) or structured professional judgment inventories (cf. Falzer, 2013; Guy, Packer, \& Warnken, 2012; Heilbrun, Yasuhara, \& Shah, 2009) derived from what Zander (2008) deemed middle-ground positions on the use of the diagnosis (First \& Halon, 2008; Frances et al., 2008; Prentky et al., 2008), and a consideration of conservative base rate estimates for the diagnosis (Wollert, 2011). Another buffer against implicit overconfidence or bias in the present context are ethical guidelines that advise forensic evaluators to make clear the limits of their evaluations and all evidence contrary to their position, including the current status and limitations of the PNOSN construct (see, e.g., Sections 2.05, 10.01, and 11.01 of the Specialty Guidelines for Forensic Psychologists; American Psychological Association, 2013).

The field might also collectively work toward solutions to the problems presented by the absence of any agreed-upon classification criteria with which evaluators can be transparent, or the fact that transparency may bear no relation to validity (i.e., an evaluator can be utterly transparent about the use of data for classification that are utterly invalid). Numerous courts have held that forensic evaluators are not bound by the four corners of the DSM system, and so the field does not need to wait until the next iteration of the DSM system to develop a clearer conceptualization and operationalization of PNOSN. Furthermore, the field is not impossibly divided; indeed, lawyers developing constructive crossexaminations recognize that opposing experts tend to agree on most expert issues, diverging on only a few (Malone \& Zwier, 2006). Perhaps experts in the area might utilize dialectical and consensus-building opportunities presented by symposia, special journal issues, and white papers that are dedicated to resolving differences to the extent possible between competing views on the subject rather than establishing any particular view as true. A consensus statement endorsed by a leading professional organization (e.g., Association for the Treatment of Sexual Abusers; see https://www.atsa.com/policy) could prove influential for both practice and research.

Delineating points of adamant disagreement versus areas of consensus might begin with a focus on conceptualization and operationalization issues, including the following. A first priority point is whether there is sufficient nonanecdotal evidence to support the possibility of a paraphilia that is not sadism and that is characterized by an anomalous sexual interest in nonconsenting persons per se. A second is whether nonconsenting targets could be clearly defined in a manner responsive to (a) the criticism that because all victims 
are nonconsenting, PNOSN is a wastebasket for all sex offenders with multiple victims, and (b) the need to refrain from scrutinizing victim behavior. Once defined generally, a third priority point is whether a sexual interest in nonconsenting targets could be delineated by a set of criteria that would facilitate a reasonable degree of diagnostic reliability.

Although there are undoubtedly shortcomings to a consensus-focused approach, it represents one possibility for reconciling some of the outstanding issues with PNOSN. If such a collective endeavor were successful, it would offer researchers a consensus-yielded conceptualization and operationalization of PNOSN to employ in their studies, which might facilitate more coherent lines of research focused on testing the reliability and validity of the proposed conceptualization and operationalization. In addition, if a consensus conceptualization and operationalization were developed that highlighted issues for which professional consensus does not exist, greater transparency by evaluators could be facilitated. For instance, the consensus document could prompt professionals to clearly indicate each controversial aspect of the diagnosis about which they make an assumption or conclusion and direct them to offer an explanation of their reasoning for each such intradiagnostic decision. Valid or not, diagnostic decision making would at least be made more transparent under this approach.

Taken together, the preceding individual- and field-level suggestions will hopefully result in more careful, qualified, transparent, and empirically grounded diagnoses of PNOSN - a diagnosis that this study suggests will almost surely be admitted into evidence and prove quite determinative in a fact finder's SVP-classification decision. Given the profound liberty consequences that can flow from a fact finder's acceptance of the PNOSN diagnosis, evaluators should welcome the opportunity for their diagnostic decision making to be subjected to greater scrutiny in the interest of advancing the best possible legal decision making (cf. DeClue, 2008).

Acknowledgments - We thank David DeMatteo for commenting on a draft of this article. The first author would also like to thank Senior Judge Benjamin Lerner, Court of Common Pleas of Philadelphia County. An earlier version of this research was presented in March 2012 at the annual meeting of the American Psychology-Law Society in San Juan, Puerto Rico. A listing of all cases utilized for this review is available upon request to the first author.

\section{Note}

1. Because SVP laws are purportedly nonpunitive and civil in nature (Kansas v. Hendricks, 1997), the term respondent is used throughout the remainder of this article to refer to the party for whom SVP classification was sought or obtained. Given the varying procedural postures of the cases reviewed, this party was in fact variously the petitioner, respondent, appellant, or appellee. Substitution of respondent for these other party names was elected in the interests of improving readability.

\section{References}

1994 N.J. Sess. Law Serv. ch. 128 (West).

2001 N.J. Sess. Law Serv. ch. 167 (West). 
Abel, G. G., Becker, J. V., Cunningham-Rathner, J., Mittelman, M., \& Rouleau, J. (1988). Multiple paraphilic diagnoses among sex offenders. Bulletin of the American Academy of Psychiatry \& the Law, 16, 153- 168.

Adam Walsh Child Protection and Safety Act of 2006, Pub. L. No. 109-248, §501, 120 Stat. 620. (2006). (codified as amended in scattered sections of $8,18,21,28$, and 42 U.S.C.).

Akerman, G., \& Beech, A. R. (2012). A systematic review of measures of deviant sexual interest and arousal. Psychiatry, Psychology and Law, 19, 118-143. doi:10.1080/13218719.2010.547161

American Academy of Psychiatry and the Law. (2005). American Academy of Psychiatry and the Law ethics guidelines for the practice of forensic psychiatry. Retrieved from http://www.aapl.org/ethics.htm

American Psychiatric Association. (1980). Diagnostic and statistical manual of mental disorders (3rd ed.). Washington, DC: Author.

American Psychiatric Association. (1987). Diagnostic and statistical manual of mental disorders (3rd ed, revised). Washington, DC: Author.

American Psychiatric Association. (1994). Diagnostic and statistical manual of mental disorders (4th ed.). Washington, DC: Author.

American Psychiatric Association. (2000). Diagnostic and statistical manual of mental disorders (4th ed., text rev.). Washington, DC: Author.

American Psychiatric Association. (2013). Diagnostic and statistical manual of mental disorders (5th ed.). Washington, DC: Author.

American Psychological Association. (2013). Specialty guidelines for forensic psychology. American Psychologist, 68, 7-19. doi:10.1037/ a0029889

Becker, J. V., Stinson, J., Tromp, S., \& Messer, G. (2003). Characteristics of individuals petitioned for civil commitment. International Journal of Offender Therapy and Comparative Criminology, 47, 185195. doi: $10.1177 / 0306624 X 03251114$

Boccaccini, M. T., Turner, D. B., \& Murrie, D. C. (2008). Do some evaluators report consistently higher or lower PCL-R scores than others? Psychology, Public Policy, and Law, 14, 262-283. doi:10.1037/ a0014523

Boccaccini, M. T., Turner, D. B., Murrie, D. C., \& Rufino, K. A. (2011). Do PCL-R scores from state and defense experts best predict future misconduct among civilly committed offenders? Law and Human Behavior, 35, 1-13.

Brown v. Watters, 599 F. 3d 602 (7th Cir. 2010).

Carlsmith, K. M., Monahan, J., \& Evans, A. (2007). The function of punishment in the "civil" commitment of sexually violent predators. Behavioral Sciences $\mathcal{E}$ the Law, 25, 437-448. doi:10.1002/ bsl.761

Cicchetti, D. V. (2001). The precision of reliability and validity estimates re-visited: Distinguishing between clinical and statistical significance of sample size requirements. Journal of Clinical and Experimental Neuropsychology, 23, 695-700. doi:10.1076/jcen.23.5.695.1249

Commonwealth v. Dengler, 890 A. 2d 372 (Pa. 2005).

D.C. Code $\S \S 22-3803$ to -3811 (2013).

DeClue, G. (2006). Paraphilia NOS (nonconsenting) and antisocial personality disorder. Journal of Psychiatry \& Law, 34, 495-514.

DeClue, G. (2008). Avoiding garbage 3: Fairness and accuracy in reporting criminal histories in sexually violent predator evaluations. Journal of Psychiatry $\mathcal{E}$ Law, 36, 431-438. 
DeMatteo, D., \& Edens, J. F. (2006). The role and relevance of the Psychopathy Checklist-Revised in court: A case law survey of U.S. courts (1991-2004). Psychology, Public Policy, and Law, 12, 214241. doi:10.1037/1076-8971.12.2.214

DeMatteo, D., Edens, J. F., Galloway, M., Cox, J., Toney Smith, S., \& Formon, D. (2013). The role and reliability of the Psychopathy Checklist-Revised in U.S. sexually violent predator evaluations: A case law survey. Law and Human Behavior. Advance online publication. doi: 10.1037/lhb0000059

Doren, D. M. (2002). Evaluating sex offenders: A manual for civil commitment and beyond. Thousand Oaks, CA: Sage.

Doren, D. M. (2006). Inaccurate arguments in sex offender civil commitment proceedings. In A. Schlank (Ed.), The sexual predator: Law and public policy-Clinical practice (Vol. 3, pp. 3-1-3-28). Kingston, NJ: Civic Research Institute.

DSM-5 and the paraphilias. (n.d.). Retrieved from http:// paraphiliasbibliography.blogspot.com/

DSM-5 paraphilias bibliography. (n.d.). Retrieved from http://www.asexualexplorations.net/home/ paraphilia_bibliography

Elwood, R. W., Doren, D. M., \& Thornton, D. (2010). Diagnostic and risk profiles of men detained under Wisconsin's sexually violent person law. International Journal of Offender Therapy and Comparative Criminology, 54, 187-196. doi:10.1177/0306624X08327305

Fabian, J. M. (2012). Neuropsychology, neuroscience, volitional impairment and sexually violent predators: A review of the literature and the law and their application to civil commitment proceedings. Aggression and Violent Behavior, 17, 1-15. doi:10.1016/j.avb.2011.07.002

Falzer, P. R. (2013). Valuing structured professional judgment: Predictive validity, decision-making, and the clinical-actuarial conflict. Behavioral Sciences $\mathcal{E}$ the Law, 31, 40-54. doi:10.1002/bsl.2043

Fanniff, A. M., Otto, R. K., \& Petrila, J. (2010). Competence to proceed in SVP commitment hearings: Irrelevant or fundamental due process right? Behavioral Sciences $\mathcal{E}$ the Law, 28, 647-670. doi:10 $.1002 / b s 1.957$

Fed. R. Evid. 104(b).

First, M. B., \& Halon, R. L. (2008). Use of DSM Paraphilia diagnoses in sexually violent predator commitment cases. Journal of the American Academy of Psychiatry and the Law, 36, 443-454.

Frances, A., \& First, M. B. (2011). Paraphilia NOS, Nonconsent: Not ready for the courtroom. Journal of the American Academy of Psychiatry and the Law, 39, 555-561.

Frances, A., Sreenivasan, S., \& Weinberger, L. E. (2008). Defining mental disorder when it really counts: DSM-IV-TR and SVP/SDP statutes. Journal of the American Academy of Psychiatry and the Law, 36, 375-384.

Graham, M., Milanowski, A., \& Miller, J. (2012). Measuring and promoting inter-rater agreement of teacher and principal performance ratings. Center for Educator Compensation Reform. Retrieved from http://cecr.ed.gov/pdfs/Inter_Rater.pdf

Grinage, B. D. (2003). Volitional impairment and the sexually violent predator. Journal of Forensic Science, 48, 861-868.

Grisso, T. (2010). Guidance for improving forensic reports: A review of common errors. Open Access Journal of Forensic Psychology, 2, 102-115.

Guy, L. S., Packer, I. K., \& Warnken, W. (2012). Assessing risk of violence using structured professional judgment guidelines. Journal of Forensic Psychology Practice, 12, 270-283. doi:10.1080/ 15228932.2012.674471

Hanson, R. K. (2010). Dimensional measurement of sexual deviance. Archives of Sexual Behavior, 39, 401-404. doi:10.1007/s10508-009- 9575-6 
Heilbrun, K., Yasuhara, K., \& Shah, S. (2009). Violence risk assessment tools: Overview and critical analysis. In R. Otto \& K. Douglas (Eds.), Handbook of violence risk assessment tools (pp. 1-18). New York, NY: Routledge Press.

In re A.M., 787 N. W. 2d 752 (N. D. 2010).

In re Civil Commitment of J.B., SVP-424-06, 2010 WL 2195707 (N. J. Super. Ct. App. Div. June 2, 2010). In re Detention of Berry, 248 P. 3d 592 (Wash. Ct. App. 2011).

In re Detention of Davenport, 157 Wash. App. 1026 (2010).

In re Richard K., No. 1 CA-MH 09-0073 SP, 2010 WL 2471240 (Ariz. Ct. App. June 17, 2010).

In re Rush, 766 N. W. 2d 720 (N. D. 2009).

In re R.Y., Jr., 957 A. 2d 780 (Pa. Super. Ct. 2008).

In re State v. Seibert, 582 N. W. 2d 745 (Wis. Ct. App. 1998).

In re Tripodes, 942 N. E. 2d 208 (Mass. App. Ct. 2011).

Jackson, R. L., \& Hess, D. T. (2007). Evaluation for civil commitment of sex offenders: A survey of experts. Sexual Abuse: A Journal of Research and Treatment, 19, 425-448.

Jackson, R. L., \& Richards, H. J. (2007). Diagnostic and risk profiles among civilly committed sex offenders in Washington State. International Journal of Offender Therapy and Comparative Criminology, 51, 313-323. doi:10.1177/0306624X06292874

Janus, E. S., \& Walbek, N. H. (2000). Sex offender commitments in Minnesota: A descriptive study of second generation commitments. Behavioral Sciences $\mathcal{E}$ the Law, 18, 343-374. doi:10.1002/10990798(200003/06)18:2/3<343::AID-BSL395>3.0.CO;2-G

Jumper, S., Babula, M., \& Casbon, T. (2012). Diagnostic profiles of civilly committed sexual offenders in Illinois and other reporting jurisdictions: What we know so far. International Journal of Offender Therapy and Comparative Criminology, 56, 838-855. doi:10.1177/0306624X11415509

Kansas v. Crane, 534 U.S. 407 (2002).

Kansas v. Hendricks, 521 U.S. 346 (1997).

Kan. Stat. Ann. §59-29a01 (2013).

King, C. (2011). Sex offender registration and community notification laws at home and abroad: Is an Internal Megan's Law good policy? New York City Law Review, 15, 117-147.

Knight, R. A. (2010). Is a diagnostic category for paraphilic coercive disorder defensible? Archives of Sexual Behavior, 39, 419-426. doi: 10.1007/s10508-009-9571-x

Lanyon, R., \& Thomas, M. L. (2008). Detection of defensiveness in sex offenders. In R. Rogers (Ed.), Clinical assessment of malingering and deception (3rd ed., pp. 285-300). New York, NY: Guilford Press.

La. Rev. Stat. Ann. §15:560 et seq. (2013).

Lave, T. R. (2011). Controlling sexually violent predators: Continued incarceration at what cost? New Criminal Law Review, 14, 213-280. Lave, T., \& McCrary, J. (2011). Assessing the crime impact of sexually violent predator laws. Manuscript in preparation. Retrieved from http://ssrn.com/abstract= 1884772

Levenson, J. S. (2004). Sexual predator civil commitment: A comparison of selected and released offenders. International Journal of Offender Therapy and Comparative Criminology, 48, 638-648. doi:10 $.1177 / 0306624$ X04265089

Levenson, J. S., \& Morin, J. W. (2006). Factors predicting selection of sexually violent predators for civil commitment. International Journal of Offender Therapy and Comparative Criminology, 50, 609629. doi: 10.1177/0306624X06287644 
Lieb, R. (1996). Washington's sexually violent predator law: Legislative history and comparison with other states (Document No. 96-12-1101). Olympia, WA: Washington Statute Institute for Public Policy. Retrieved from http://www.wsipp.wa.gov/rptfiles/WAsexlaw.pdf

Lloyd, C. D., Clark, H. J., \& Forth, A. E. (2010). Psychopathy, expert testimony and indeterminate sentences: Exploring the relationship between Psychopathy Checklist-Revised testimony and trial outcome in Canada. Legal and Criminological Psychology, 15, 323-339. doi:10.1348/135532509 X468432

Malone, D. M., Zwier, P. J. (2006). Effective expert testimony. United States of America: National Institute for Trial Advocacy.

McLawsen, J. E., Scalora, M. J., \& Darrow, C. (2012). Civilly committed sex offenders: A description and interstate comparison of populations. Psychology, Public Policy, and Law, 18, 453-476. doi:10 $.1037 / \mathrm{a} 0026116$

Melton, G. B., Petrila, J., Poythress, N. G., Slobogin, C., Lyons, Jr., P. M., \& Otto, R. K. (2007). Psychological evaluations for the courts: A handbook for mental health professionals and lawyers (3rd ed.). New York, NY: Guilford Press.

Mercado, C. C., Schopp, R. F., \& Bornstein, B. H. (2005). Evaluating sex offenders under sexually violent predator laws: How might clinicians conceptualize the notion of volitional impairment? Aggression and Violent Behavior, 10, 289-309. doi:10.1016/j.avb.2003.12.003

Miller, H. A., Amenta, A. E., \& Conroy, M. A. (2005). Sexually violent predator evaluations: Empirical evidence, strategies for professionals, and research directions. Law and Human Behavior, 29, 2954. doi: 10.1007/s10979-005-1398-y

Morse, S. J. (1994). Culpability and control. University of Pennsylvania Law Review, 142, 1587-1660. doi:10.2307/3312464

Murphy, M., Galloway, M., DeMatteo, D., \& Krauss, D. A. (2013, March). A national survey of state sexually violent person (SVP) legislation: Procedures, policy and practice. Poster presented at the meeting of the American Psychology-Law Society, Portland, OR.

Murrie, D. C., Boccaccini, M., Johnson, J., \& Janke, C. (2008). Does interrater (dis)agreement on Psychopathy Checklist scores in sexually violent predator trials suggest partisan allegiance in forensic evaluation? Law and Human Behavior, 32, 352-362. doi:10.1007/s10979-007-9097-5

Murrie, D. C., Boccaccini, M. T., Turner, D., Meeks, M., Woods, C., \& Tussey, C. (2009). Rater (dis)agreement on risk assessment measures in sexually violent predator proceedings: Evidence of adversarial allegiance in forensic evaluation? Psychology, Public Policy, and Law, 15, 19-53. doi:10.1037/a0014897

O'Donohue, W., Regev, L. G., \& Hagstrom, A. (2000). Problems with the DSM-IV diagnosis of pedophilia. Sexual Abuse: Journal of Research and Treatment, 12, 95-105.

Ohio Rev. Code Ann. § 2971 et seq. (West 2013).

Olson, K. C. (2009). Principles of legal research (successor to How to Find the Law, 9th ed.). St. Paul, MN: Thomson Reuters.

Packard, R. L., \& Levenson, J. S. (2006). Revisiting the reliability of diagnostic decisions in sex offender civil commitment. Sex Offender Treatment, 1, 1-15. Retrieved from http://www.sexual-offendertreatment.org/index.php?id=50\&type=123

Parkman v. Sex Offender Screening and Risk Assessment Committee, 307 S. W. 3d 6 (Ark. 2009).

People v. C. M., No. 22/2008, 2009 WL 1351208 (N. Y. Sup. Ct. Mar. 31, 2009).

People v. Orozco, (2008), No. B199439, 2008 WL 4404262 (Cal. Ct. App. Sept. 30, 2008). 
Petrila, J. (2008). Because they do horrible things: Fear, science, and the erosion of civil liberties in sexually violent predator proceedings. Journal of Psychiatry \& Law, 36, 359-387.

Prentky, R. A., Coward, A. I., \& Gabriel, A. M. (2008). Muddy diagnostic waters in the SVP courtroom. Journal of the American Academy of Psychiatry and the Law, 36, 455-458.

Prentky, R. A., Janus, E., Barbaree, H., Schwartz, B., \& Kafka, M. (2006). Sexually violent predators in the courtroom: Science on trial. Psychology, Public Policy, and Law, 12, 357-393. doi:10.1037/10768971.12.4.357

Quinsey, V. L. (2010). Coercive paraphilic disorder. Archives of Sexual Behavior, 39, 405-410. doi:10 .1007/s10508-009-9547-x

Rufino, K. A., Boccaccini, M. T., Hawes, S., \& Murrie, D. C. (2012). When experts disagreed, who was correct? A comparison of PCL-R scores from independent raters and opposing forensic experts. Law and Human Behavior, 36, 527-537. doi:10.1037/h0093988

Schopp, R. F., Pearce, M., \& Scalora, M. J. (1998). Expert testimony and sexual predator statutes after Hendricks. Expert Evidence, 6, 1-21. doi:10.1023/A:1008820318005

Schopp, R. F., Scalora, M. J., \& Pearce, M. (1999). Expert testimony and professional judgment: Psychological expertise and commitment as a sexual predator after Hendricks. Psychology, Public Policy, and Law, 5, 120-174. doi:10.1037/1076-8971.5.1.120

Schopp, R. F., \& Sturgis, B. J. (1995). Sexual predators and legal mental illness for civil commitment. Behavioral Sciences \& the Law, 13, 437-458. doi:10.1002/bsl.2370130402

Seling v. Young, 531 U.S. 250 (2001).

Slobogin, C., Rai, A., \& Reisner, R. (2009). Law and the mental health system: Civil and criminal aspects. St. Paul, MN: West.

Spitzer, R. L., Gibbon, M., Skodol, A. E., Williams, J. B. W., \& First, M. B. (2002). DSM-IV-TR casebook: A learning companion to the Diagnostic and Statistical Manual of Mental Disorders, Fourth Edition, Text Revision. Washington, DC: American Psychiatric Publishing. doi:10.1176/appi.books.978158 5622665

Stemler, S. E. (2004). A comparison of consensus, consistency, and measurement approaches to estimating interrater reliability. Practical Assessment, Research \& Evaluation, 9(4). Retrieved from http:// PAREonline.net/getvn.asp? $\mathrm{v}=9 \& \mathrm{n}=4$

Stern, P. (2010). Paraphilic coercive disorder in the DSM: The right diagnosis for the right reasons. Archives of Sexual Behavior, 39, 1443-1447. doi:10.1007/s10508-010-9645-9

Stern, P. (2011). Wollert (2011) demonstrates again how ideology taints scientific debate. Archives of Sexual Behavior, 40, 1099-1100. doi:10.1007/s10508-011-9844-z

Stinson, J. D., \& Becker, J. V. (2008). Assessing sexual deviance: A comparison of physiological, historical, and self-report measures. Journal of Psychiatric Practice, 14, 379-388. doi:10.1097/01.pra .0000341892 .51124 .85

Thornton, D. (2010). Evidence regarding the need for a diagnostic category for a coercive paraphilia. Archives of Sexual Behavior, 39, 411-418. doi:10.1007/s10508-009-9583-6

Uebersax, J. (2009). Raw agreement indices. Retrieved from http://www.john-uebersax.com/stat/ raw.htm

United States v. Carta, 592 F. 3d 34 (1st Cir. 2010).

United States v. Comstock, 130 S. Ct. 1949 (2010).

United States v. Graham, 683 F. Supp. 2 d 129 (D. Mass. 2010). 
Viljoen, J. L., MacDougall, E. A. M., Gagnon, N. C., \& Douglas, K. S. (2010). Psychopathy evidence in legal proceedings involving adolescent offenders. Psychology, Public Policy, and Law, 16, 254-283. doi:10.1037/a0019649

Walsh, T., \& Walsh, Z. (2006). The evidentiary introduction of Psychopathy Checklist-Revised assessed psychopathy in U.S. courts: Extent and appropriateness. Law and Human Behavior, 30, 493507. doi:10.1007/s10979-006-9042-z

Westlaw database directory. (2013). Retrieved from http://directory.westlaw.com/

Wettstein, R. M. (1992). A psychiatric perspective on Washington's sexually violent predators statute. University of Puget Sound Law Review, 15, 597-633.

Wettstein, R. M. (2005). Quality and quality improvement in forensic mental health evaluations. Journal of the American Academy of Psychiatry and the Law, 33, 158-175.

Winick, B. L. (1998). Sex offender laws in the 1990s: A therapeutic jurisprudence analysis. Psychology, Public Policy, and Law, 4, 505-570. doi:10.1037/1076-8971.4.1-2.505

Winsmann, F. (2012). Assessing volitional impairment in sexually violent predator evaluations. Sexual Offender Treatment, 7, 1-14. Retrieved from http://www.sexual-offender-treatment.org/103.html

Witt, P. H. (2010). Forensic report checklist. Open Access Journal of Forensic Psychology, 2, 233-240.

Witt, P. H., \& Conroy, M. A. (2009). Evaluation of sexually violent predators. New York, NY: Oxford University Press.

Wollert, R. (2007). Poor diagnostic reliability, the Null-Bayes Logic Model, and their implications for sexually violent predator evaluations. Psychology, Public Policy, and Law, 13, 167-203. doi:10.1037/ 1076-8971.13.3.167

Wollert, R. (2011). Paraphilic coercive disorder does not belong in the DSM-5 for statistical, historical, conceptual, and practical reasons [Letter to the Ed.]. Archives of Sexual Behavior, 40, 1097-1098. doi: 10.1007/s10508-011-9814-5

Zander, T. K. (2005). Civil commitment without psychosis: The law's reliance on the weakest links in psychodiagnosis. Journal of Sexual Offender Civil Commitment, 1, 17-82.

Zander, T. K. (2008). Inventing diagnosis for civil commitment of rapists. Journal of the American Academy of Psychiatry and the Law, 36, 459-469. 